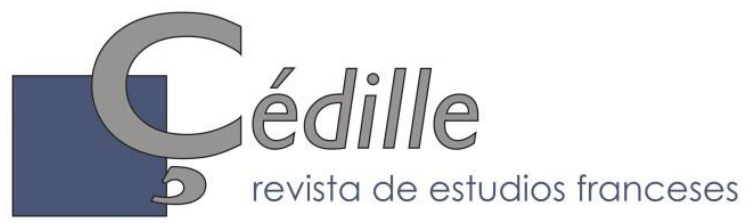

ISSN: 1699-4949

$n^{0} 18$ (otoño de 2020)

Monografías 11

Epistemocrítica: análisis literario y saber científico

Amelia Gamoneda Lanza \& Francisco González Fernández, editores científicos

\title{
La neurohermenéutica de la sospecha. Una aproximación teórica
}

\author{
Renata GAMBINO \\ Grazia Pulvirenti \\ Universitá degli Studi di Catania \\ renatagambino@gmail.com \\ ORCID: 0000-0002-4713-8555 \\ grapulvir@gmail.com \\ ORCID: 0000-0002-7341-8817
}

\begin{abstract}
Resumen
Este artículo revisita la hermenéutica de la sospecha de Paul Ricœur considerándola un acto de interpretación inquisitivo basado en la intersubjetividad y destinado a desvelar significados ocultos y latentes del texto literario. En nuestra opinión, el marco teórico de Ricœur es relevante para los estudios neurocognitivos actuales aplicados a la literatura en cuanto a las cuestiones de encarnación (embodiment), simulación corporal e interpretación de significados textuales latentes y ocultos tras los evidentes. La práctica de la sospecha de Ricœur supone uno de los dos polos de nuestra investigación actual del texto literario, siendo el segundo la aproximación neurohermenéutica. Desde la perspectiva de lo que aquí definimos como la neurohermenéutica de la sospecha, el lector se convierte en intérprete y cuestiona el texto y los distintos niveles de sus rasgos superficiales cuando advierte claves inferenciales destacadas que desvelan significados secundarios. El proceso de construcción del significado depende de un acto creativo acaecido en la imaginación del lector, que encarna la (re-)construcción mental de la situación descrita en el texto. Por tanto, la interpretación de la sospecha no se apoya en el texto, el autor, el lector o el contexto cultural o cognitivo, sino en una relación compleja y dinámica que pivota alrededor de las facultades encarnadas comunes a todo ser humano. Proponemos que Ricœur, especialmente en las derivas postcríticas de la actualidad, puede resultar de gran ayuda para redefinir el placer de descifrar los mundos ficticios de la literatura en tanto que pone a prueba al lector para "jugar" con el texto literario, concebido como una terra incognita de múltiples e inagotables significados.
\end{abstract}

Palabras clave: Neurohermenéutica, Hermenéutica de la sospecha, Modelos situacionales, Corporalización.

\section{Résumé}

Dans cet article on revient sur l'herméneutique de la suspicion de Paul Ricœur en l'envisageant comme un acte d'interprétation basé sur l'intersubjectivité et destiné à dévoiler des significations cachées et latentes du texte littéraire. À notre avis, le cadre

* Artículo recibido el 25/02/2020, aceptado el 28/10/2020.

Traducción del inglés de Benito García-Valero. 
théorique de Ricœur est marquant pour les études neurocognitives actuelles appliquées à la littérature en ce qui concerne les questions d'incarnation (embodiment), simulation corporelle et interprétation des significations textuelles latentes et cachées derrière celles qui sont évidentes. La pratique de la suspicion de Ricœur suppose l'un des pôles de notre recherche actuelle du texte littéraire, l'autre étant l'approche neuroherméneutique. Dans la perspective de ce qui est ici défini comme la neuroherméneutique de la suspicion, le lecteur devient un interprète et questionne le texte et les différents niveaux de ses traits superficiels quand il remarque des clés inférentielles saillantes dévoilant des significations secondaires. Le processus de construction de la signification dépend d'un acte créatif advenu dans l'imagination du lecteur, qui incarne la (re)construction mentale de la situation décrite dans le texte. Par conséquent, l'interprétation de la suspicion ne repose pas sur le texte, l'auteur, le lecteur ou le contexte culturel ou cognitif, mais sur un rapport complexe et dynamique pivotant autour des facultés incarnées communes à tout être humain. Nous proposons que Ricœur, particulièrement dans les dérives postcritiques actuelles, peut être d'un grand secours pour redéfinir le plaisir de déchiffrer les mondes fictionnels de la littérature dans la mesure où il met à l'épreuve le lecteur pour " jouer » avec le texte, envisagé comme une terra incognita de significations multiples et inépuisables.

Mots-clés : Neuroherméneutique, Herméneutique de la suspicion, Modèles situationnels, Incarnation.

\begin{abstract}
In this paper we draw back to Ricœur's hermeneutics of suspicion, considered as an act of mistrustful interpretation based on intersubjectivity and aiming at disclosing latent and hidden meanings in the literary text. In our opinion Ricœur's theoretical frame is relevant for present-day neurocognitive studies about literature, with regard to the issues of embodiment, bodily simulation and interpretation of textual latent meanings hidden beyond the manifest ones. Ricœur's practice of suspicion is one of the two poles of our present inquiry about literary text, while the second is our neurohermeneutic approach. In the perspective of what we here define as neurohermeneutics of suspicion, the reader becomes an interpreter, questioning the text with regard to its multilayered surface features as marking inferential clues unveiling secondary meanings. The meaning-making process depends on a creative act of the reader's imagination embodying the mental (re)construction of the situation described by a text. Therefore, suspicious interpreting does not rely in either the text, the author, the reader or the cultural and cognitive context, but in their complex and dynamic relationship, pivoting around the common embodied faculties of being a human. We claim that particularly in the postcritical venture, Ricœur's hermeneutics, may be helpful in refiguring the pleasure of deciphering the fictional worlds of literature, challenging the reader to "play" with the literary text intended as a terra incognita of inexhaustible multiple meanings.
\end{abstract}

Keywords: Neurohermeneutics, Hermeneutics of Suspicion, Situation Models, Embodiment.

\title{
1. Introducción
}


Este artículo pretende enfatizar la importancia del principio de Ricœur de la "hermenéutica de la sospecha", a tenor de los estudios neurocognitivos actuales de la literatura que abordan las cuestiones de la intersubjetividad como consecuencia de la encarnación o corporalización (conocida en inglés como embodiment), y de la interpretación como facultad cognitiva que reconfigura creativamente significados textuales latentes, ocultos tras los evidentes. La "lectura de la sospecha" (o "lectura suspicaz") puede considerarse, por un lado, una actitud intelectual desmitificadora y, por otro, una desconfianza crítica en la aproximación a los textos literarios que hace posible obtener significados que de otra manera serían inaccesibles, y además amplificar el placer de leer literatura.

En la relativamente nueva empresa de las poéticas cognitivas, la narración es considerada una actividad fundamental de la mente durante la generación de conocimiento, y el lenguaje es estudiado a partir de sus rasgos cognitivos, que construyen nuestra forma de habitar el mundo y de extraerle un sentido (Lakoff \& Johnson, 1980; Turner, 2014). Uno de los discursos mejor articulados sobre la construcción de significados fue desarrollado en términos filosóficos durante los años setenta y ochenta del siglo pasado por el filósofo francés Paul Ricœur, que entrelazó la reflexión antropológica y la fenomenología hermenéutica con unas comprensiones precoces sobre la intersubjetividad, el concepto de mente humana y sus procesos imaginativos y de construcción de significado.

Nos centraremos en la concepción del lenguaje de Ricœur como espacio de significaciones interrelacionadas complejas, en el que los significados no son solo explícitos y unívocos, sino también ocultos y plurívocos. Tomando en consideración la doble existencia de "significados aparentes y latentes", propuso una "hermenéutica de la sospecha" concibiéndola como una desmitificación de significados ilusorios y como una restauración de significados latentes (Ricœur, 1965: 19). El principio de la sospecha conlleva una crítica radical contra la ilusión de la verdad positivista, tal y como demuestra con su análisis del pensamiento de los tres "maestros de la sospecha" (Freud, Marx y Nietzsche), capaces de "dégage[r] l'horizon pour une parole plus authentique, pour un nouveau règne de la Vérité, non seulement par le moyen d'une critique 'destructrice', mais par l'invention d'un art d'interpréter" (Ricœur, 1965: 41-42). La interpretación es por tanto concebida como el resultado de un proceso dialógico. El entendimiento es el resultado de una reconstrucción continua de significado que se debe a una relación intersubjetiva con los otros y las cosas, por medio de cierta herencia lingüística que nos permite establecer una relación de intercambio y diálogo con ellos.

¿Por qué consideramos la teoría de la sospecha de Ricœur especialmente prometedora en el marco de la actual empresa transdisciplinar que vincula las humanidades con los estudios neurocognitivos? La hermenéutica de la sospecha abre una nueva perspectiva en el proceso de lectura de textos literarios, y sorprendentemente sale al encuentro de muchos de los resultados en que derivan las funciones de la mente-cerebro durante la experiencia de la lectura. Por tanto, en nuestro enfoque neurohermenéutico, la lectura de la sospecha puede considerarse un acto de 
interpretación basado en la intersubjetividad y en el desvelamiento de significados múltiples.

El método de Ricœur para conseguir una lectura rigurosa "realizada a contracorriente" (Felski, 2011: 222) ha sido recuperado recientemente no solo por los estudios religiosos y la antropología (para una revisión del asunto, véase Felski, 2009; 2011; 2015), sino también por las aproximaciones críticas a la literatura. Estos últimos estudios pretenden enfatizar la complejidad significativa velada y latente de los textos literarios y establecer "no solo un ejercicio cognitivo sino una orientación [...], una sensibilidad o disposición distinguidas cuyos parámetros excedan los pormenores de su contenido intelectual [...], un ethos que cuestione y se autocuestione incansablemente" (Felski, 2011: 219) ${ }^{1}$. Con respecto a la crítica literaria, Felski (2015: 18) afirma que aún no se ha escrito "una historia amplia de la interpretación suspicaz" debido a la tensión desmitificadora que tendría y a la radical apertura que requeriría. Algunos académicos han reintroducido el concepto de "sospecha" en la crítica literaria con un sentido positivo (véase para una revisión de este proceso Felski, 2011), y han destacado su similitud con la actitud detectivesca y la teoría de juegos, aunque otros estudiosos, como Eve Kosovsky Sedgwick (1997), han tachado este tipo de lectura suspicaz de "paranoide" y restringida por métodos de la teoría crítica ya superados. En sentido opuesto argumentamos nosotras que, en el contexto de la deriva postcrítica actual, la hermenéutica de Ricœur puede resultar útil para reconfigurar el placer de descifrar los mundos ficcionales de la literatura, pues alienta al lector a "jugar" con el texto literario, concebido como una terra incognita de múltiples e inagotables significados.

El marco en el que inscribimos el concepto de sospecha no es el de la crítica literaria postestructuralista o deconstruccionista, sino el de los estudios neurocognitivos $^{2}$ de la literatura. En este marco, podría decirse que la actitud de la sospecha predice algunos desarrollos teóricos relativos a dos cuestiones: 1) La del círculo neurohermenéutico, contemplado como una dinámica ejecutada por el lector suspicaz que cuestiona el texto en un proceso cognitivo que requiere la participación de su sistema sensomotor (Gambino \& Pulvirenti, 2018; 2019). 2) La de la intersubjetividad, concebida en términos de encarnación (embodiment). Desde esta nueva perspectiva, abordaremos cómo el texto literario activa en el lector suspicaz la construcción y desvelamiento de significados inscritos en las claves inferenciales que emergen de elementos lingüísticos, estilísticos y retóricos puestos de relieve (en inglés, foregrounded features). Este proceso causa que el lector reactive la respuesta fisiológica producida por tales elementos textuales, y reconfigure la relación entre cuerpo y cerebro desde una concepción encarnada de la experiencia lectora basada en la intersubjetividad. La teoría de la intersubjetivi-

${ }^{1}$ Con el fin de facilitar la lectura, traducimos todas las citas de textos que no se encuentran originalmente escritos en francés.

2 Para conocer otros intentos de vincular las teoría de Ricœur con los estudios cognitivos, remitimos al artículo de Geoffrey Dierckxens (2018). 
dad ya estaba presente en Ricœur (1965, 376): "tous nos rapports au monde ont une constitution intersubjective". En su opinión, toda la problemática del significado depende del fenómeno de la intersubjetividad: "Tout sens a finalement des dimensions intersubjectives ; toute 'objectivité' est intersubjective, en tant que l'implicite est ce qu'un autre peut expliciter" (Ricœur, 1965: 376). La cuestión de la intersubjetividad se halla en el núcleo de las últimas teorías de la cognición entendida como encarnada, insertada, accionada y extendida, tal y como han sido recientemente formuladas en el concepto de la "cognición de las 4E" (Newen et $a l ., 2018)$, llamada así por entender la intrincación de cuatro cualidades de la cognición aludidas mediante sus iniciales en inglés (embodied, embedded, enacted, extended), y que hacen referencia a la interrelación de cerebro, cuerpo, entorno y acción. En este marco, la función del cuerpo, del entorno y de la acción adquieren una relevancia extraordinaria especialmente en lo que respecta a la percepción, la intencionalidad, la cognición social, la producción cultural y la evolución (Newen et al., 2018). La encarnación o corporalización se halla en el núcleo de un cambio radical en la manera de estudiar los procesos cerebrales que se activan durante la interacción con el entorno, y también durante las experiencias estéticas, como la lectura (Gallese, 2017; 2018). Los procesos cognitivos se conciben a partir de su base corporal, mientras que la experiencia estética se considera derivada del fenómeno de la simulación encarnada, entendida como fuente de empatía y de acción (Gallese, 2013; 2016; 2018b; 2018c). El concepto de encarnación sitúa en el núcleo de la reflexión el fenómeno de la intersubjetividad basada en la intercorporalidad; constituye la base de cualquier interacción humana, de cualquier acuerdo social y de cualquier forma de comunicación, incluida la experiencia estética, dado que conlleva un acuerdo sobre la definición de un conjunto de significados o sobre la evaluación de una situación (Gallese \& Cuccio, 2015). La asunción de que la intersubjetividad, y por tanto la creación de significado, están basadas en dinámicas fisiológicas, neurológicas y culturales comunes a todos los seres humanos nos lleva a reconsiderar la hermenéutica del texto literario desde nuevos fundamentos.

En otro lugar hemos desarrollado el enfoque neurohermenéutico de la literatura considerando el texto literario en su construcción jerárquica y como respuesta al sistema efectivo de la mente encarnada desde una perspectiva tanto cognitiva como fisiológica (Gambino \& Pulvirenti, 2018; 2019). Según nuestras hipótesis, los múltiples niveles operantes en la superficie del texto literario demandan la activación de procesos corporales, emocionales y cognitivos específicos en la mente del lector. Inconscientemente, el autor es capaz de inducir procesos cognitivos específicos en el lector pues comparte con él las mismas estructuras fisiológicas y cognitivas humanas básicas. Al inscribir este concepto en el marco de la teoría de Ricœur proponemos que su concepto de sospecha puede ser considerado un principio heurístico enraizado en la intersubjetividad y la intercorporalidad. Una neurohermenéutica de la sospecha es aquella que confiere al lector la posibilidad de cuestionar el texto en relación con significados que están 
ocultos por no estar expresados directamente por la mente del autor, sino que se hallan diversamente estratificados en los rasgos superficiales del texto y pueden ser distinguidos por claves inferenciales que aparecen marcadas gracias a la puesta en relieve de ciertos elementos fonológicos, morfosintácticos o retóricos.

\section{La mente suspicaz}

Ricœur teorizó el principio de la sospecha en su libro De l'interprétation : essai sur Freud (1965) como una tensión hacia la desmitificación de falsas verdades inspirándose en los tres maestros de la sospecha: Freud, que desveló las dinámicas de la psique; Nietzsche, que cuestionó la realidad biológica de las asunciones de la falsa moral; y Marx, que denunció el determinismo económico. En sus trabajos, el mismo acto de entender es hermenéutico, igual que lo es el acto de descifrar significados según la existencia de un nivel de expresión primario o secundario. Por consiguiente, la hermenéutica estabiliza la condición doble de la conciencia anclada en la antonimia "caché-montré", "simulé-manifesté" (Ricœur, 1965: 42). En el caso de los tres pensadores, la acción de descifrar se relaciona con un trabajo opuesto de cifrado, producido respectivamente por el ser social (Marx), la voluntad de poder (Nietzsche) y el inconsciente (Freud). Para deconstruir "la ilusión de conciencia" derivada de tales elementos, Marx, Nietzsche y Freud construyeron sus procedimientos de desmitificación basándose en la práctica de la sospecha.

En el nivel lingüístico, la sospecha es entendida por Ricœur como la actitud que emerge de interpretar la existencia de significados dobles en enunciados y sistemas de signos. Alison Scott-Baumann afirma que el uso de Ricœur del concepto de sospecha no es estable. En su opinión, la expresión "hermenéutica de la sospecha" no coincide con el significado preciso que le atribuye la investigación de los maestros de la sospecha. Scott-Baumann (2009: 59) afirma también que el uso de este término por otros estudiosos no coincide siempre con la intención original de Ricœur:

La expresión "hermenéutica de la sospecha" se usa a menudo en filosofía, teología y literatura aunque frecuentemente se malentiende: se atribuye por error al libro de Ricœur sobre Freud y se tiene casi como un sinónimo de la expresión "maestros de la sospecha". [...] La expresión no se suele contextualizar como parte de un importante debate sobre el significado que Ricœur emprendió.

Estas afirmaciones requieren una breve contextualización del problema antes de profundizar en la argumentación que Ricœur expone en su libro $D e$ l'interprétation : essai sur Freud (1965). Scott-Baumann refiere la dicotomía postulada por Gadamer entre "hermenéutica en el sentido clásico", es decir, la interpretación de los significados manifiestos del texto, y la "crítica y sospecha radical hacia el entendimiento y la interpretación". La dicotomía entre "hermenéutica del respeto" y "hermenéutica de la sospecha" no puede ser superada, según 
Gadamer, porque la última implica un desafío radical a la "validez de las ideas" (Gadamer, 1984: 313).

Por el contrario, en nuestra opinión, la cuestión crucial sobre la sospecha de Ricœur es la asociación de una tensión negativa (dudar y desenmascarar) con una positiva, que es el proceso de recuperar significado, dado que el lenguaje en sí mismo es concebido por Ricœur como "un modo de ser" (Ricœur, 1971: XV). Los dos procesos, el de sospechar y el de restaurar significado, son diferentes, pero están íntimamente relacionados y construyen un palimpsesto para todo el marco de la fenomenología hermenéutica de Ricœur. El mismo Ricœur no concebía los dos tipos de hermenéutica como opuestos: "Una está orientada al resurgimiento de símbolos arcaicos y la otra hacia el surgimiento de nuevos símbolos y figuraciones emergentes" (Ricœur, 1976: 56).

La práctica de los maestros de la sospecha lucha en primer lugar contra el acto inconsciente de engañar a otros o a nosotros mismos en lo relativo a motivaciones, acciones o creencias. Deconstruyeron el principio de lo consciente, lo autoconsciente y el autoconocimiento. Ya durante el proceso cognitivo básico de percibir y elaborar perceptos el ser humano es engañado por el hecho de que la percepción no es neutral, sino influida por muchos aspectos, especialmente las experiencias subjetivas y las memorias, el deseo y el narcisismo (Ricœur, 1965). Desde esta perspectiva, la gran contribución de los maestros de la sospecha consistió en desenmascarar el falso principio de la conciencia y en poner en acción una práctica de rechazo a los significados aparentes, dudando profundamente de sus motivaciones auténticas, y partiendo en busca del significado de lo que es ser humano.

Retomamos ahora la hermenéutica de la sospecha -que es la que resulta relevante para nuestra investigación-, para recordar que se ocupa del ámbito de los significados, concebidos como un sustrato oculto bajo la capa de la apariencia. También Ricœur (1971: XV) considera el proceso de autoconocimiento como:

[...] siempre indirecto y procedente de la interpretación de signos dados al margen de mí en la cultura y en la historia [...]. El sujeto de la autocomprensión es un regalo de la comprensión en sí mismo y de la invitación del significado inscrito en el texto.

El significado se sitúa por tanto en palabras y signos. La hermenéutica de la sospecha contempla la cuestión del significado en cualquier forma de sistema sígnico, desde el lingüístico a aquellos que expresan constructos humanos, como figuras, símbolos, historias y subjetividad, concebidas no como modelos impersonales, sino como cuerpos vivientes insertados en contextos histórico-políticos específicos.

Aunque Ricœur argumentó sobre los límites del autoconocimiento, creía en el poder humano de descifrar signos. Este credo gnoseológico en la lectura de signos es una actitud fundamental en su fenomenología hermenéutica, anticipada en La symbolique du mal (1960) y desarrollada en De l'interprétation : essai sur 
Freud (1965), así como en sus estudios sobre hermenéutica. Dio gran importancia a la interpretación de símbolos como "el lugar de mayor densidad":

Es en el símbolo donde el lenguaje se desvela en su fuerza mayor y con su mayor completitud. Dice algo independiente de mí, y dice más de lo que yo puedo entender. El símbolo es sin duda el lugar privilegiado del excedente de significado (Ricœur, 1971: XVI).

Ricœur echa la vista atrás hasta el tratado de Aristóteles Peri Hermêneias (Sobre la interpretación) y arguye que ya para el filósofo griego interpretar significaba "decir algo de algo", y que esta significación en sí misma estaba presente en sustantivos, verbos, proposiciones y en el discurso en general (Ricœur, 1965: 30). Por tanto, el acto de la interpretación comienza durante el mismo proceso de crear un enunciado, dado que "est interprétation tout son émis par la voix et doté de signification - toute phônè sematztikè, toute vox significativa" (Ricœur, 1965: 30). Para Aristóteles, la interpretación mira al enunciado, puesto que "nous disons le réel en le signifiant ; en ce sens nous l'interprétons" (Ricœur, 1965: 31). La "signification de la phrase", es decir, la proposición declarativa, ya es una interpretación del mundo: "La rupture entre la signification et la chose est déjà consommée avec le nom et cette distance marque la place de l'interprétation" (Ricœur, 1965: 31). Sobre la pluralidad de significados que emerge de la unicidad de la esencia de la vida, argumenta que la unidad de lo referencial no genera una única significación: “ces sens multiples de l'être sont les 'catégories' même - ou les 'figures' - de la prédication ; aussi cette multiplicité traverse-t-elle tout le discours" (Ricœur, 1965: 32).

Además de la práctica específica de la sospecha concebida como una clave para llegar a significados diferentes, Ricœur recoge un tipo de historia de la hermenéutica que comienza por la exégesis bíblica, para la cual la interpretación textual es tenida como una precisa "ciencia de las reglas", y va más allá con la extensión del concepto de hermenéutica como "interpretación naturae". El punto de inflexión de su concepto de hermenéutica es el doble concepto de la restauración y manifestación del significado:

D'un côté, l'herméneutique est conçue comme la manifestation et la restauration d'un sens qui m'est adressé à la façon d'un message, d'une proclamation ou, comme on dit quelquefois, d'un kerygme [...] elle est conçue comme une démystification, comme une réduction d'illusions (Ricœur, 1965: 35-36).

Recuperando la epoché de Husserl, Ricœur ancla su teoría en la verdad de los símbolos considerados como un cumplimiento de la intención significadora; de esta asunción deriva los conceptos de sentido segundo (significado secundario) como habitantes del primer sentido (significado primario o literal). Para Ricœur (1965: 36), 
[...] l'herméneutique [est] mue par cette double motivation : volonté de soupçon, volonté d'écoute ; vœu de rigueur, vœu d'obéissance; nous sommes aujourd'hui ces hommes qui n'ont pas fini de faire mourir les idoles et qui commencent à peine d'entendre les symboles. Peut-être cette situation, dans son apparente détresse, est-elle instructive: peut-être l'extrême iconolasme appartient-il à la restauration du sens.

Ricœur consigue una comprensión universal del conocimiento humano como una tensión concebida como eros, deseo y amor, que entiende consustancial a la naturaleza humana. De esta asunción ontológica deriva la necesidad de considerar también el acto de reflexionar como un acto de interpretación enraizado en el acto de existir "dans des signes épars dans le monde" (Ricœur, 1965: 54). De hecho, el modo de existir de los seres humanos en la filosofía de Ricœur está profundamente relacionado con el lenguaje, tal y como afirma taxativamente: "les hommes sont nés au sein du langage, au milieu de la lumière du logos 'qui éclaire tout homme venant au monde"" (Ricœur, 1965: 38). De esta premisa se deduce que el acto de usar el lenguaje puede considerarse desde diferentes perspectivas: ontológica, filosófica (en cuanto a la cuestión de la conciencia), hermenéutica (en cuanto a la cuestión de los símbolos y la interpretación de los dobles significados); todas ellas unificadas por la tensión que explicábamos al comienzo del párrafo.

Para los propósitos que acometemos, nos interesa particularmente asumir las teorías de Ricœur en lo que respecta a lo simbólico, donde nuestra autocomprensión está determinada por la expresividad, la temporalidad y la importancia ontológica que los símbolos confieren a la vida humana. Para nosotras es especialmente relevante en la teoría de la sospecha de Ricœur la cuestión epistemológica, que trata específicamente con el concepto del doble significado en el lenguaje y con lo que él llama "lo simbólico". Su idea de lo simbólico se retrotrae a la definición de Cassirer, quien lo concibió en relación con los procesos cognitivos de la mente humana, implicado en la organización de la experiencia del sujeto y del mundo: 'Le 'symbolique' désigne le commun dénominateur de toutes les manières d'objectiver, de donner sens à la réalité (Ricœur, 1965: 20). Por tanto, Ricœur usa lo simbólico en un sentido amplio para indicar las herramientas culturales a través de las cuales aprehendemos y organizamos la cognición: "langage, religion, art, science" (Ricœur, 1965: 20). Estas herramientas están presentes en sistemas de signos construidos sobre la posibilidad de abarcar un "grado mayor" de significación si son comparados con otros signos sensoriales. Lo simbólico es así un ámbito de expresiones con significado doble o plurívoco. La inestabilidad derivada exige un trabajo de interpretación que intercepte los muchos significados adheridos a la textura semántica:

Il y a symbole lorsque le langage produit des signes de degré composé où le sens, non content de désigner quelque chose, désigne un autre sens qui ne saurait être atteint que dans et par sa visée (Ricœur, 1965: 25). 
La función simbólica también es concebida como un acto de "médiation par le moyen de laquelle l'esprit, la conscience, construit tous ses univers de perception et de discours" (Ricœur, 1965: 19). Ricœur afirma que los símbolos alcanzan tres ámbitos principales: el primero, el más dominante, es el sagrado, en el cual las acciones y las expresiones de las experiencias cotidianas designan análogamente otras experiencias en el universo del discurso, como los rituales de purificación (lavar, quemar, enterrar) o símbolos (el sendero sinuoso, el cielo, el agua): "L'expressivité du monde vient au langage par le symbole comme double sens" (Ricœur, 1965: 24). El segundo ámbito de emergencia de lo simbólico es el onírico, en el cual se certifica el hecho de que el significado manifiesto, que puede ser reconstruido en la narración del sueño durante el estado de vigilia, es solo un espejo de significados ocultos que deben ser desvelados. El tercer ámbito de lo simbólico es el de "l'imagination poétique" (Ricœur, 1965: 24), y así Ricœur no concibe la imaginación como un proceso de presentar cosas ausentes o de formar imágenes mentales, sino como un acto lingüístico que crea una nueva dimensión del ser a través del poder expresivo del lenguaje en "l'origine de l'être parlant" (Bachelard apud Ricœur, 1965: 24).

¿Qué tienen en común estos diferentes ámbitos de lo simbólico? El principio es el analogon. Confiere relevancia al cambio del significado literal al significado en "segundo grado": "je suis porté par le sens premier, dirigé par lui vers le sens ; le sens symbolique est constitué dans et par le sens littéral qui opère l'analogie en donnant l'analogue" (Ricœur, 1965: 26).

Esta relación no es estable y puede variar, puede resultar "inocente" o una "distorsión ingeniosa": cuestión importante para nuestra interpretación de textos literarios, puesto que ambas formas -la analogía inocente y la distorsión ingeniosa (o camuflaje) - pueden estar presentes en diferentes proporciones, según las diferentes tipologías textuales y las intenciones comunicativas del autor. Por ejemplo, la estratificación del significado en los poemas es más compleja que en la narración, dada su formalización linguiística extrema y la presencia de niveles superpuestos de desfamiliarización (fonológica, morfosintáctica, niveles retóricos) que crean campos con una elaboración formal más alta dentro del texto. La diferente proporción entre analogía inocente y distorsión ingeniosa puede también verse como el resultado de la elección precisa de un autor. En cualquier caso, Ricœur considera que el primer significado -explícito en el nivel de la expresión literal- disfraza o desvela lo que define como "significado segundo". Queda en manos del lector descubrir el significado segundo llevando a cabo un proceso de cuestionamiento escéptico y descubriendo la ambigüedad que caracteriza lo simbólico: 'L'ambiguïté du symbole n'est pas alors un défaut d'univocité, mais la possibilité de porter et d'engendrer des interprétations adverses et cohérentes chacune en elle-même" (Ricœur, 1965: 478).

Desde esta perspectiva, afirmamos que lo que postula Ricœur sobre lo simbólico podría ajustarse a los textos literarios si los consideramos dispositivos complejos de significados plurívocos, es decir, texturas verbales en las que los 
significados coexisten y no son dados de forma inmediata, sino que están ocultos, escondidos tras expresiones aparentemente simples. En su artículo "Existence et herméneutique" (Ricœur, 1969), define lo simbólico como "toute structure de signification où un sens direct, primaire, littéral, désigne par surcroît un autre sens indirect, secondaire, figuré, qui n'est peut être appréhendé qu'à travers le première" (Ricœur, 1969: 16). El acto de entender va a la par con el de interpretar y está enraizado en el doble significado del lenguaje, dado que "l'interprétation appartient organiquement [...] à son double sens" (Ricœur, 1965: 27).

¿Cómo se puede entender el significado segundo? La cuestión nos ha llevado a poner en relación el concepto de Ricœur de significados plurívocos y el principio de sospecha con el enfoque neurohermenéutico que hemos desarrollado en estudios previos (Abramo, Gambino \& Pulvirenti, 2017; Gambino \& Pulvirenti, 2018; 2019). Es común considerar el texto literario como dispositivo y fuente de significados abundantes. Esta "épaisseur du sens multiple" (Ricœur, 1965: 56) exige el proceso de comprensión, y dirige un acto de interpretación que consiste "moins à supprimer l'ambiguïté qu'à la comprendre et à en expliciter la richesse" (Ricœur, 1965: 56). La presencia de múltiples significados en un texto literario activa en el lector el proceso de interpretación, es decir, provoca la necesidad de estabilizar el horizonte de la comprensión: "le surcroît même du sens, par rapport à l'expression littérale qui met en mouvement l'interprétation" (Ricœur, 1965: 27). La estructura del texto literario, con sus ambigüedades, invoca a la interpretación: "[...] il y a quelque chose à désenvelopper, à désimpliquer [...]" (Ricœur, 1965: 27). El doble significado pide a la mente del lector el proceso de "destapar" las ambigüedades textuales, extrayendo sentido al texto.

\section{Significados múltiples}

La cuestión de la polisemia ha sido abordada en diferentes ámbitos de la crítica literaria y también en investigaciones de la estética de la recepción. Yuri Lotman ya interpretaba el "lenguaje poético" -refiriéndose en general al literariocomo un sistema de "segundo grado" en comparación con el lenguaje natural, basándose para ello en la peculiar relación entre los rasgos lingüísticos que producen múltiples significados (Lotman, 1977: 12). Desde esta perspectiva estructuralista, Lotman entiende que el significado y sus implicaciones ideológicas dependen de la estructura poética del lenguaje: "El contenido-idea de una obra es su estructura" (Lotman, 1977: 12). Los rasgos "estructurales" del texto literario, su "modelo artístico" específico -tal y como lo construye el autor- muestra el mundo del autor y, en consecuencia, su manera de pensar sobre el mundo mismo (Lotman, 1977: 12). Lotman entendía el texto poético metaestructurado como un texto diferente al comunicativo o al informativo a causa de sus rasgos precomunicativos, es decir, el texto literario no pretende comunicar, sino activar experiencias a través de sus rasgos formales. La relación entre idea-contenido y estructura refleja la relación entre la vida y los mecanismos biológicos del mundo vivo: la vida es la función del organismo vivo y no puede concebirse fuera de él: 
La vida, propiedad principal de un organismo vivo, no puede pensarse fuera de su estructura física; es una función de este sistema efectivo. El científico literario que espere comprender una idea que fuera independiente del sistema del autor para modelar el universo, independiente de la estructura de la obra de arte, es un científico idealista que intenta separar la vida de la estructura biológica concreta cuya misma función es esa vida (Lotman, 1977: 12).

Los rasgos formales no son elementos meramente ornamentales o persuasivos, son ambiguos y comunicativos al mismo tiempo, o lo que es lo mismo, producen un "ruido" (Paulson, 1988) que conduce a la emergencia de infinitos niveles nuevos de significado (Lotman, 1977: 66) y estimula un "anhelo" creativo en el lector. De hecho, la naturaleza organizativa del texto poético exhibe una potencialidad infinita que depende del peculiar juego "entre el orden redundante y la sorpresa informativa" (Paulson, 1988: 43). El texto poético va más allá del sistema "palabra-signo" causal y lineal ya que atrae al lector hacia la creación de nuevos sistemas y códigos significantes secundarios o terciarios. Esta multiplicación de los niveles del significado, de las relaciones y de los códigos constituye la esencia del lenguaje literario y suscita la emergencia de significado a partir del proceso de la lectura literaria: "Lo que es extrasistémico en la vida se representa como polisistémico en el arte" (Lotman, 1977: 72). Las peculiares cualidades de un texto literario son emergentes, dependientes del contexto y complejas. El lector no desvela las diversas capas semánticas implicadas en el texto literario, de manera que algunas permanecen sin descodificar o, como Paulson dice, "ruidosas" (Paulson, 1988). El texto literario, más que ningún otro tipo de texto, produce en el lector la activación de dinámicas únicas y específicas entre todos los elementos del texto para poder construir significado.

\section{Encarnación e intersubjetividad}

Puede concebirse la literatura como un fenómeno arraigado en la corporalidad y como un proceso que refleja las complejas interacciones entre el cerebro, el cuerpo, el entorno y el contexto histórico, cultural y social (Thelen, 2001). El lector puede descubrir los mecanismos inferenciales y representacionales más refinados que regulan la creación de un mundo ficcional con inagotables significaciones, mediante el accionamiento (enaction) de las representaciones literarias del texto en su calidad sensomotora, "encarnando" el mundo ficcional con sus emociones, memorias y demás experiencias vitales.

En la base del complejo y solo parcialmente conocido proceso de lectura de un texto literario radica el fenómeno teorizado y definido por Vittorio Gallese como "simulación encarnada" (embodied simulation). Su funcionamiento se basa en la simulación motora, la cual es parte de un fenómeno descrito por Gallese como "cognición motora", a través de la cual las habilidades cognitivas, como la identificación de las intenciones motoras en el comportamiento de los demás, así como la anticipación de acciones, se fundamentan y posibilitan gracias a la arqui- 
tectura funcional del sistema motor, el cual a su vez está organizado en términos de acciones motoras con propósitos específicos:

Nuestra capacidad de crear sentido a partir de las acciones, emociones y sensaciones de los demás antes de filtrarlas por la razón depende de la simulación encarnada, un mecanismo funcional a través del cual las acciones, las emociones y las sensaciones que vemos activan nuestra propia representación interna de estados corporales que están asociados a estos estímulos sociales, como si estuviésemos afectados por una acción similar o experimentando una emoción o sensación similar. La activación de las mismas áreas cerebrales durante la experiencia de acciones, emociones o sensaciones, sean en primera o en tercera persona, parece indicar que, además de la evaluación cognitiva explícita o el estímulo social, probablemente haya un mecanismo filogenéticamente anterior que permite la comprensión experiencial y directa de los objetos y del mundo interior de los demás (Freedberg \& Gallese, 2007: 198).

Los procesos motores implican no solo los componentes dinámicos o cinéticos de las acciones, sino también las representaciones motoras de los propósitos de estas. Las acciones son percibidas al nivel del sistema motor en la interacción con los demás. De hecho, hay una relación anatómica y funcional muy próxima entre la acción y la semántica, lo cual supone hablar de una integración sensomotora entre la acción del sujeto en relación con un objeto y su significado: algunas áreas del cerebro (incluidas la frontal, la parietal y la temporal) producen algo parecido a una "copia" de los patrones motores con el fin de ejecutar acciones que corresponden con cosas en el mundo, y lo hacen en relación con la codificación de significado de tales cosas dadas en la realidad (Gallese et al., 1996: 593-609). Según el concepto de simulación encarnada, el común denominador que constituyen el cuerpo físico y sus características permite inferir emociones y estados de ánimo mediante la lectura:

Muchas pruebas convincentes muestran que los humanos, cuando procesamos el lenguaje, activamos el sistema motor tanto en el nivel fonoarticulatorio como en el semántico. Cuando escuchamos palabras pronunciadas en alto o miramos a alguien que nos habla, nuestro sistema motor simula los gestos empleados para producir esas mismas palabras. Además, el procesamiento de acciones relacionadas con expresiones lingüísticas activa regiones del sistema motor congruentes de manera sematotópica con el contenido semántico procesado. Leer o escuchar una frase que describe la acción de una mano activa la representación motora de esa misma acción (Gallese \& Cuccio, 2015: 11).

En consecuencia, el sustrato corporal o, en otras palabras, fisiológico y emocional, amplifica la posibilidad de "inferir" cualidades significantes del texto 
más allá de las categorías retóricas. La posibilidad de este tipo de "inferencia" se basa en el concepto de "intersubjetividad" que participa en el proceso de la simulación encarnada. Gallese y Cuccio (2015: 8) teorizan sobre el concepto de intersubjetividad como consecuencia del descubrimiento de las neuronas espejo:

Una de las consecuencias del descubrimiento de las neuronas espejo fue la posibilidad de derivar la subjetividad de la intersubjetividad al nivel de descripción subpersonal. La sensación de subjetividad se desarrolla precozmente en primer lugar por un sujeto que es ante todo físico y corporal, y que está constituido precisamente por la posibilidad de interactuar y actuar con otros. La simulación encarnada puede proveer la base neurobiológica de formas más tempranas de intersubjetividad a partir de las que se desarrolla el sujeto. El descubrimiento de las neuronas espejo y del mecanismo simulador podría por tanto acentuar que ser un sujeto también implica serlo junto a otro. [...]. El descubrimiento de las neuronas espejo nos da una noción de base empírica de intersubjetividad connotada primero y principalmente como intercorporalidad -la resonancia mutua de comportamientos sensomotores intencionalmente significativos-.

La intersubjetividad implica entonces nuestra habilidad de compartir emociones y sensaciones con los demás, convocando las mismas áreas visceromotoras y sensomotoras del cerebro que se activan cuando observamos a otras personas que tienen esas mismas emociones o sensaciones. La intersubjetividad es la base de la simulación encarnada que nos permite "sentir por" y "empatizar con" otros seres humanos. El proceso se activa especialmente en la literatura cuando el lector experimenta imágenes y personajes ficticios como si fueran parte del mundo real. Esta perspectiva cambia de manera radical nuestra forma de entender la producción y recepción literarias, pues enfatiza el papel central que juega la participación sensomotora de nuestro cuerpo en la experiencia estética.

\section{Las dinámicas de la neurohermenéutica de la sospecha}

La simulación encarnada dirige las complejas dinámicas que el autor ejecuta durante la elaboración de su experiencia del mundo en representaciones mentales transformadas en lenguaje, deviniendo de esta manera en símbolos y metáforas de un mundo en "segundo grado", el mundo ficticio, caracterizado por lo que Ricœur definió como doble significado. La simulación encarnada dirige también los actos del lector ${ }^{3}$, quien es guiado por el texto para crear su propio mundo

\footnotetext{
3 Según el enfoque aplicado, el lector se entiende como "receptor implícito" -destinatario presupuesto e ideal que existe en la imaginación del autor y puede ser reconstruido a través de información extratextual-, o bien como "lector abstracto" en referencia a lo que Mukarovsky concibió como entidades "abstractas" de la obra o, finalmente, según la teoría de la recepción, como "lector real", el que recibe y modifica las imágenes mentales al tiempo que lee en concordancia con su conocimiento subjetivo y su experiencia, respondiendo también al texto de diferentes mane-
} 
imaginario según su percepción, trasfondo cultural, experiencias, memorias, emociones y facultades imaginativas (Abramo, Gambino \& Pulvirenti, 2017). Atribuye Ricœur al lector el proceso de creación de significado concibiéndolo como una reconfiguración del mundo mental del autor (Ricœur, 1983) y como un desvelamiento de significados secundarios que surgen de los primarios.

¿Cómo pueden desvelarse significados secundarios asumiendo una actitud suspicaz? Nos retrotraemos a la hermenéutica de Schleiermacher (1998) para proponer la descripción de la relación entre autor, texto y lector como una dinámica circular que conlleva procesos corporales, emocionales y cognitivos; en otras palabras, como un "círculo neurohermenéutico". Esta perspectiva holística pretende observar fenomenológicamente el proceso de creación de significado del lector mientras lee un texto literario mediante la reconfiguración de algunos de los procesos mentales-corporales, de las actitudes e intenciones conceptuales puestas en juego por el autor, que organiza sus propios mundos en términos de "lenguaje formal" (o la forma del lenguaje) de la literatura (para Lotman, opuesto al lenguaje natural; Lotman, 1977). Desde esta perspectiva, el significado no depende ni del texto, ni del autor, ni del lector, ni tampoco del contexto cognitivo o cultural, sino de la relación compleja y dinámica que los implica a todos en un acto productivo de la imaginación. Visto desde nuestro enfoque neurohermenéutico (Gambino y Pulvirenti, 2018; 2019), el texto es considerado un dispositivo cognitivo que refleja dinámicas mentales fundamentales, que son suscitadas selectivamente por el autor (este aspecto de la intencionalidad aparece desarrollado en Freeman, 2007: 1179) por medio de rasgos lingüísticos, estilísticos y retóricos manifestados en la forma del lenguaje literario. Tales rasgos afectan al cuerpo y a los procesos imaginativos, emocionales y cognitivos del lector, al tiempo que este identifica las claves inferenciales del texto, comenzando por el análisis de los rasgos puestos en relieve de manera estructural, estilística o retórica. Así, la cuestión de la recepción de los textos literarios, ya estudiada por los métodos de la estética de la recepción (Iser, 1976; 1991), converge de forma transdisciplinar con el análisis lingüístico, estilístico y semántico de la crítica literaria y con el análisis cognitivista del discurso. El enfoque neurohermenéutico devuelve al autor y al lector la presencia de su cuerpo y de sus funciones cerebrales en el acto creativo e interpretativo, y así reintroduce el principio de intencionalidad en la producción y recepción literarias.

Al vincular el principio de sospecha de Ricœur con la neurohermenéutica, podemos focalizar los elementos intencionales escondidos en el texto que ponen en marcha el círculo neurohermenéutico; en otras palabras, el proceso que acontece durante el acto de lectura por el cual los elementos intencionalmente escondidos por el autor en el texto excitan la mente del lector con el fin de activar su propio proceso exegético ante la pluralidad de significados. Desde la perspecti-

ras y desde distintos niveles de conciencia. Para conocer una exposición más detallada de estos contenidos, véase The Living Handbook of Narratology en la edición online que utiliza Miall (2006). 
va de Ricœur, ello supone decir que la tarea del lector es bucear en el textoestructura para descubrir lo que permanece latente o ambiguo en el nivel literal. Esta dimensión de la sospecha es lo que transforma a un lector común en un intérprete suspicaz:

[...] l'interprétation, dirons-nous, est le travail de pensée qui consiste à déchiffrer le sens caché dans le sens apparent, à déployer les niveaux de signification impliqués dans la signification littérale; je garde ainsi la référence initiale à l'exégèse, c'est-à-dire à l'interprétation des sens cachés. Symbole et interprétation deviennent ainsi des concepts corrélatifs ; il y a interprétation là où il y a sens multiple, et c'est dans l'interprétation que la pluralité des sens est rendue manifeste (Ricœur, 1969: 16-17).

Desde el punto de vista de la neurohermenéutica de la sospecha, el lector inicia el proceso dinámico movido por la tensión de descifrar las claves inferenciales en relación con su situación textual, sus dominios subtextuales y con un amplio trasfondo de construcciones lingüísticas, ideológicas, sociales, políticas y culturales, no porque el texto sea "síntoma" de condiciones sociales o económicas, sino porque vela y desvela el contexto en el que es situado y con el que interactúa a causa de la relación intersubjetiva entre lectores y autores.

La interacción del lector con el mundo real hace que el proceso neurohermenéutico se convierta en un sistema abierto que implica al autor, al texto y al lector en una dinámica de continuo ocultamiento y desvelamiento (Ricœur, 1975). Este proceso puede ser descrito como un diálogo exquisito, basado en la asunción de que el procesamiento del lenguaje se corresponde con la activación de las mismas regiones sensomotoras que participan en la percepción y en la acción, tal y como proponen las teorías anteriormente mencionadas de la simulación encarnada.

Para llegar a una comprensión del texto que vaya más allá del nivel superficial y active el principio de sospecha, el lector ha de capturar y "descifrar" las "claves inferenciales" inscritas en el texto como trazos de intenciones autorales ${ }^{4}$, que guían al lector a la determinación de significados latentes. Las inferencias acaecen durante la lectura del texto y están relacionadas con los procesos de extraer conclusiones a partir de evidencias. La actitud interpretativa, implicada en el principio de sospecha, guía al lector en la integración del significado literal del texto con conocimientos previos de diversa índole, y se basa en la "asunción de que la comprensión es un proceso constructivo que refleja interacciones entre lector, texto y tarea en un contexto sociocultural concreto" (Goldman, McCarthy \&

\footnotetext{
${ }^{4}$ Esta idea requiere reintroducir una categoría que el estructuralismo y las investigaciones cuantitativas habían rechazado a priori, y que es el estudio de la intención autorial como acicates para la interpretación textual. En nuestra opinión, esta categoría debe ser reintroducida una vez haya sido considerado el concepto de simulación encarnada postulado por Vittorio Gallese, dada su relevancia para el acto de leer e interpretar.
} 
Burkett, 2015: 387). La adopción de la actitud interpretativa depende de la tarea avalada por el lector y también en gran medida de los conocimientos previos del lector sobre el mundo, el tema, las características del texto, los estándares de coherencia, así como la intención comunicativa del autor. En las teorías contemporáneas del discurso, la actitud interpretativa se caracteriza por la comprensión y la representación; en otras palabras, el nivel literal - o texto base- o bien refleja la información explícita dada en el texto o bien puede ser inferida con el uso de conocimientos previos. La generación de la situación modelo propuesta por el texto literario supone que el lector vaya más allá de lo que resulta explícito en el texto y necesite operar en un nivel más profundo o global (por ejemplo: elementos psicológicos de los personajes o inferencias interpretativas temáticas; Goldman, McCarthy \& Burkett, 2015):

Obtener significado de un texto o poema literario requiere algo más que comprender palabras y frases, en concreto, la (re-)construcción mental de la situación descrita en el texto modelos de simulación- que hipotéticamente emergen a través de la integración del conocimiento del mundo que tenga el lector con la información explícitamente presente en el texto (Jacobs \& Williams, 2018: 2).

Los patrones específicos del lenguaje o los recursos retóricos pueden evidenciar las intenciones comunicativas del autor. Por tanto, la actitud interpretativa bebe del significado literal pero conecta o asocia lo literal con el conocimiento contextual, las tendencias generales para abordar la naturaleza humana, los principios de la vida y las experiencias personales, etc. Ello acontece sobre la base de resonancia mutua de comportamientos sensomotores intencionalmente significativos y sobre principios que parecen gobernar la manera en que opera el mundo. Los estudios empíricos han desvelado que, al asumir una actitud interpretativa, las inferencias textuales están derivadas principalmente del texto y no tanto simplemente basadas en el texto, es decir, el acto interpretativo (el ejercicio de la sospecha) activa facultades personales, creativas e imaginativas en el lector (Kintsch \& van Dijk, 1978; Van Dijk \& Kintsch, 1983).

Caracterizan a los textos literarios un nivel de significado superficial y otro más profundo, lo cual implica decir que el texto superficial conscientemente "usa convenciones que proveen de pistas para acceder a un significado más profundo" (Goldman, McCarthy \& Burkett, 2015: 395). Algunos elementos del texto literario están cargados de potencial relevancia, aparecen en posiciones privilegiadas, están acentuados por medios fonológicos, sintácticos o semánticos, crean rupturas, parecen oscuros, fuera de lugar, resultan metafóricos, simbólicos, satíricos, etc. En definitiva, están "puestos en relieve" y por tanto generan claves inferenciales para la actitud interpretativa (McCarthy, 2015; McCarthy \& Goldman, 2017).

Identificar estas claves requiere que el lector suspicaz amalgame información de distintas partes del texto, contrastándola con sus conocimientos previos, produciendo imágenes mentales personales y activando el proceso de 
creación de significado que trasciende los lindes del significado aparente y unívoco.

Las claves inferenciales emergen del fenómeno de los elementos puestos en relieve, tal y como teorizaron Miall y Kuiken (1994), y provocan desfamiliarización. Estos rasgos deberían ser detectados en relación tanto con la coherencia interna del texto como con los marcos epistemológicos contingentes reconstruidos por la investigación en especificidades históricas, sociales, culturales, filosóficas, lingüísticas y estéticas de la época. Una actitud interpretativa implica por lo general la participación activa del lector para trascender el texto o la situación específica y elaborar inferencias explicativas de las claves que operan en el texto. Esto determina respuestas específicas en el proceso de lectura, suscitando en el lector el ejercicio de la sospecha. En este sentido, consideramos centrales los rasgos puestos de relieve, pues alrededor de ellos el estudio del texto literario puede ser interpretado en su desvelo de lo que resulta latente, plurívoco o ambiguo.

La expresión "puesto de relieve" -como dijimos, del inglés foregrounding, presumiblemente introducida por Garvin (1964: 19) como una traducción del término checo aktualisce de Mukarovksy (véase Leech, 1969)- parece estar íntimamente conectada con el segundo nivel de Rosenblatt de la comprensión (interpretación) del texto según la teoría lingüística de la poesía de Leech. En términos lingüísticos, la figura puesta de relieve es escogida por el lector entre todos los elementos que forman el trasfondo [background] lingüístico del texto, y la considera "la parte más cautivadora y significativa del mensaje, y la interpreta en contraste con los patrones esperables del trasfondo" (Leech, 1969: 57). En opinión de Miall y Kuiken, los elementos de relieve causan supuestamente una impresión de desfamiliarización en el lector, refieren un rango de efectos estilísticos, y son considerados "marcas de literariedad" (Miall \& Kuiken, 1994: 337). Sus hipótesis proponen que "cuando la percepción se desautomatiza, el lector emplea los sentimientos que son evocados para encontrar o crear un contexto en el que los aspectos desfamiliarizados de la historia pueden ser ubicados" (Miall \& Kuiken, 1994: 392). Los elementos desfamiliarizados rompen a menudo las expectativas creadas en la narración y con gran frecuencia implican: a) la secuencia temporal (flashbacks, desplazamientos temporales, compresiones o expansiones del tiempo); b) la organización espacial (la narración situada en mundos de fantasía, o desarrollada en mundos paralelos, o entornos que obedecen a condiciones diferentes a las impuestas por las leyes naturales); c) la motivación de los personajes (por ejemplo, la finalidad de acciones que no están claramente definidas o se contradicen); d) el personaje (en cuanto a los aspectos de su identidad, intenciones o comportamientos); e) la relación causa-efecto (eventos esperados que no suceden, o inesperados que suceden y rompen la lógica de la trama) (Norenzayan et al., 2006). La identificación de rasgos puestos de relieve ha inspirado una gran cantidad de experimentos empíricos sobre la lectura literaria (para una revisión de estos puede consultarse Schrott \& Jacobs, 2011) que han intentado averiguar si las figuras retóricas motivan formas específicas de experiencia emocional y suscitan 
el proceso de creación de significado y la respuesta estética y, en caso positivo, cómo lo hacen.

Con el fin de estudiar la importancia de estos elementos a la hora de interpretar el texto, de crear las imágenes mentales correspondientes y de activar el proceso de creación de significado en el lector, hemos desarrollado la Matriz de Evaluación del Relieve (FAM por sus siglas en inglés, Foregrounding Assessment Matrix) para intentar definir y destacar los rasgos puestos de relieve en los niveles subléxicos, léxicos, interléxicos y supraléxicos, presentándolos junto a categorías fonológicas, morfosintácticas y retóricas. Aunque somos conscientes del carácter simplificador de estas categorías, este análisis ha revelado que las estrategias que más relieve generan se aplican en las mismas partes del texto, dando espacio a lo que hemos llamado "campos de densidad", partes del texto donde la mayor parte de los rasgos puestos de relieve se concentran y se convierten en una especie de "atractores de atención" (Gambino \& Pulvirenti, 2018: 95-100). Estos campos de alta relevancia con respecto al trasfondo ${ }^{5}$ del texto parecen adquirir importancia a la hora de predecir la respuesta estética y cognitiva del lector, y de correlacionarla con activaciones semánticas más fuertes y la adquisición de significado (Gambino \& Pulvirenti, 2018: 95-100). Los campos de densidad son plurívocos y ambiguos porque son el resultado de solapar rasgos puestos de relieve, y suscitan la adopción de la actitud interpretativa suspicaz para adquirir significados ocultos o secundarios. Los campos de densidad son por tanto hitos en el texto que también pueden ser considerados pistas que inducen "sospecha" y que pueden ser detectadas según el "principio cognitivo de relevancia" (Sperber \& Wilson, 1995) analizando las representaciones mentales del "estado situacional" denotado por parte del texto (Zwann, 2016: 1028) y desautomatizando el procesamiento intuitivo o situacional.

Los campos de densidad, que poseen una diversidad cualitativa mayor que la de los estímulos cotidianos (Cupchik, 1994), pueden ser considerados por tanto como activadores del sistema sensomotor del lector, dado que el lector acciona imaginativamente una experiencia propia interna para crear mentalmente el mundo ficticio. A pesar de las predisposiciones individuales hacia las imágenes, las investigaciones recientes han demostrado que todos los lectores experimentan imágenes mentales basadas en cualquier modalidad sensorial (véase Kintsch, 1988; Kuzmicova, 2014). Mediante la creación de una imagen mental de aquello que está propuesto en el tramo puesto de relieve del texto (Zwaan, 2016: 1028), el

\footnotetext{
${ }^{5}$ Se ha dedicado muy poca investigación al estudio del papel del trasfondo de los textos literarios, aquello que Iser llamó el "repetorio" del texto. Proponemos que centrarnos en los rasgos puestos de relieve requiere tomar en cuenta el trasfondo porque el proceso de creación de significado del lector resulta de la relación entre elementos puestos en contraste. Solo contemplando el "repertorio" de un texto será posible evaluar los rasgos textuales "desfamiliarizados" que se apartan de las "líneas base" ya sea en el nivel lingüístico, retórico o semántico o en el nivel que corresponde con la coherencia textual y las relaciones vitales, expresadas en modelos de situación específicos, como el tiempo, el espacio, la entidad, la causación o la motivación (Graesser \& Zwann, 1995).
} 
lector se convierte en "cuerpo experimentador": fantasmas, memorias y emociones personales cobran vida para poder accionar la representación sensomotora individual de esa experiencia. A la luz de la investigación realizada por Zwaan (2016), la representación sensomotora y simbólica, suscitada por la actitud interpretativa, se influyen mutuamente. Por tanto, parece cabal asumir que leer un texto requiere no solo del proceso cognitivo de desplegar las figuraciones simbólicas -en términos de Ricœur-, sino también de la activación de las representaciones sensomotoras.

Según nuestra hipótesis, las diferentes claves inferenciales y los rasgos puestos de relieve "guían" al lector "para rellenar los vacíos" del texto en cuanto latencias, ambigüedades y fluctuaciones, con el fin de estabilizar la experiencia imaginativa enraizada en la realidad encarnada por el contexto cognitivo, emotivo y las memorias de cada persona.

La sospecha, inducida por dichos rasgos, activa al lector para desplegar el condensado mundo de rasgos lingüísticos, estilísticos y retóricos, y permite que su cuerpo y su percepción interpreten las claves inferenciales que nacen de los elementos puestos de relieve a través de la común cualidad de poseer un cuerpo. De hecho, el acto de interpretar textos literarios comienza con un autor que procesa imaginativamente una experiencia vivida que deviene símbolo en un texto y llega al intérprete suspicaz que hay en el lector, capaz de "desplegar" los significados latentes u ocultos en un rango completo de elementos físicos, emocionales y cognitivos de una experiencia vital plena.

\section{Conclusiones}

El objetivo de este ensayo no es probar cómo la hermenéutica de la sospecha de Ricœur resulta atractiva para la crítica literaria actual. En realidad, este artículo intenta recuperar la práctica de leer textos "a contracorriente" con el fin de destacar la circularidad dialógica de leer e interpretar en una dinámica que implica al autor y sus intenciones comunicativas, al texto con todos sus rasgos, al lector con su cuerpo y su mente, y al contexto cultural. Desde este punto de vista, leer literatura puede considerarse y estudiarse como un proceso accionado, encarnado e insertado por el cual tanto la comprensión como la respuesta estética dependen fundamentalmente de la posibilidad del autor de interceptar e influir en el lector a través del lenguaje, gracias al hecho de que comparten cualidades básicas y fundamentales como son tener un cuerpo humano y unos procesos mentales que son comunes a todos. Hemos recuperado la hermenéutica de la sospecha de Ricœur puesto que entendemos que abre nuevas perspectivas a los procesos cognitivos encarnados en la actitud interpretativa, y sale al encuentro de estudios neurológicos, teóricos y cognitivos recientes sobre el acto de la lectura literaria.

En el cruce de la práctica de la sospecha de Ricœur y del enfoque neurohermenéutico es posible destacar las dinámicas circulares en un proceso creativo único que afecta a la percepción, la emoción, la memoria, la cognición y la imaginación. La representación ficcional de los sentimientos y de las emociones, así 
como las acciones de las emociones, producen una intensa actividad en la imaginación que apela a la simulación corporal (Johnson, 1987; Cuccio, Carapezza \& Gallese, 2013) y al sistema sensomotor. El lector, llevado por la actitud de sospecha, es capaz de descubrir y desplegar las claves inferenciales del mundo ficcional del texto literario, centrándose en los rasgos contraintuitivos, y respondiendo con su implicación encarnada al texto, simulando el mundo literario imaginativamente a través del cuerpo y de la mente.

Esta perspectiva nos permite obtener nuevas interpretaciones del texto literario, buscando significados latentes y escondidos que la mente humana necesita construir o recuperar para estabilizar los elementos inestables del mundo real, y también los del literario. El análisis fenomenológico de este proceso permite destacar cómo la interpretación de textos literarios induce al lector a una experiencia dialógica basada en las cualidades universales de compartir un lenguaje y un cuerpo situado en el mundo. Llevado por la actitud de la sospecha, el lector es capaz de accionar el texto dejando que resuenen dos mundos imaginativos (el del autor y el del lector) (Zwaan et al., 2010) durante la experiencia interpretativa, recuperando los significados latentes a través de un proceso de cuestionamiento de los rasgos manifiestos, las ambigüedades y las claves inferenciales ocultas dispuestas en varios niveles en la superficie del texto. La sospecha es el motor de este proceso que recompensa el esfuerzo interpretativo con el placer estético de descubrir y construir significados, dando sentido a la existencia humana en este mundo.

\section{REFERENCIAS BIBLIOGRÁFICAS}

ABRAMO, Federica, Renata GAMBINO \& Grazia PUlVIRENTI (2017): «Cognitive Literary Anthropology and Neurohermeneutics. A Theoretical Proposal». Enthymema, 8, 44-62.

CuCCIO, Valentina, Marco CARAPEZZA \& Vittorio GALleSE (2013), «Metafore che risuonano. Linguaggio e corpo tra filosofia e neuroscienze». EC. Rivista dell'Associazione Italiana Studi Semiotici, 7:17, 69-74.

CUPCHIK, Gerald (1994): «Emotion in Aesthetics: Reactive and Reflective Models». Poetics, 23, 177-188.

DIERCKXSENS, Geoffrey (2018): «Imagination, narrativity and embodied cognition: Exploring the possibilities of Paul Ricœur's hermeneutical phenomenology for enactivism». Filosofia Unisinos, 19:1, 41-49.

FELSKI, Rita (2009): «After Suspicion». Profession, 28-35.

FELSKI, Rita (2011): «Suspicious Minds». Poetics Today, 32:2, 215-234.

FELSKI, Rita (2015): The Limits of Critique. Chicago, University of Chicago Press.

FREEDBERG, David \& Vittorio GALLESE (2007): «Motion, Emotion and Empathy in Aesthetic Experience». Trends in Cognitive Sciences, 11:5, 197-202. 
FREEMAN, Margaret (2007): «Cognitive Linguistic Approaches to Literary Studies. State of the art in Cognitive Poetics», in D. Geeraerts \& H. Cuyckens (eds.), The Oxford Handbook of Cognitive Linguistics. Oxford/Nueva York, Oxford University Press, 1175-1202.

GADAMER, Hans-Georg (1984): «The Hermeneutics of Suspicion». Man and World, 17, 313-323.

GALLESE, Vittorio et al. (1996): «Action Recognition in the Premotor Cortex». Brain, 1996, 119, 593-609.

GALLESE, Vittorio (2013): «Corpo non mente. Le neuroscienze cognitive e la genesi di soggettività e intersoggettività». Educazione sentimentale, 20, 8-24.

GALLESE, Vittorio (2016): «Finding the Body in the Brain. From Simulation Theory to Embodied Simulation», in B. McLaughlin \& H.K. Kornblith (eds.), Goldman and His Critics. Hoboken, John Wiley \& Sons, 297-314.

GALLESE, Vittorio (2017): «Visions of the Body: Embodied Simulation and Aesthetic Experience». Aisthesis, 1, 1, 41-50.

GALLESE, Vittorio (2018a): «Embodied Simulation and its Role in Cognition». Reti, saperi, linguaggi, 7:1, 31-46.

GALlESE, Vittorio (2018b): «The Problem of Images: A View from the Brain-Body». Phenomenology and Mind, 14, 70-79.

GALLESE, Vittorio (2018c): «Naturalizing Aesthetic Experience. The Role of (Liberated) Embodied Simulation». Projections, 12:2, 50-59.

GALlese, Vittorio \& Valentina CUCCIO (2015). «The Paradigmatic Body - Embodied Simulation, Intersubjectivity, the Bodily Self, and Language», in T. Metzinger \& J. M. Windt (eds.), Open MIND, Fráncfort del Meno, MIND Group, 1-22.

GAMBINO, Renata \& Grazia PULVIRENTI (2018): Storie, menti, mondi. Approccio neuroermeneutico alla letteratura. Milán, Mimesis.

GAmbinO, Renata \& Grazia PUlVIRENTI (2019): «Neurohermeneutics. A Transdisciplinary Approach to Literature». Gestalt Theory, 41:2, 185-200.

Garvin, Paul (1964): A Prague School Reader on Esthetics, Literary Structures and Style, Washington D.C., Georgetown University Press.

GOLDMAN, Susan, Kathryn MCCARTY \& Candice BURKETT (2015): «Interpreting Inferences in Literature», in E.J. O'Brien, A.E. Cook \& R.F. Lorch Jr. (eds), Inferences during Reading. Cambridge, Cambridge University Press, 386-415.

GRAESSER, Arthur C. \& Rolf A. ZWAAN (1995): «Inference Generation and the Construction of Situation Models», in C.A. Weaver, S. Mannes \& C.R. Fletcher (eds.), Discourse Comprehension: Essays in Honour of Walter Kintsch. Nueva York-Londres, Routledge, 117-140.

ISER, Wolfgang (1976): Der Akt des Lesens: Theorie ästhetischer Wirkung. Múnich, Fink Verlag.

JACOBS Arthur M. \& Roel M. WILLEMS (2018): «The Fictive Brain: Neurocognitive Correlates of Engagement in Literature». Review of General Psychology, 22:2, 147160. URL: https://doi.org/10.1037/gpr0000106. 
JoHnson, Mark (1987): The Body in the Mind: The Bodily Basis of Meaning, Imagination and Reason. Chicago, University of Chicago Press.

KINTSCH, Walter (1988): «The Role of Knowledge in Discourse Comprehension: A Construction-Integration Model». Psychological. Review, 95:2, 163-182.

KINTSCH, Walter \& Teun A. VAN DiJK (1978): «Toward a Model of Text Comprehension and Production». Psychological Review, 85, 363-394.

KUZMIČOVÁ, Anezka (2014): «Literary Narrative and Mental Imagery: A View from Embodied Cognition». Style, 48:3, 275-293.

LAKOFF, George \& Mark JOHNSON (1980): Metaphors We Live By. Chicago, University of Chicago Press.

LEECH, Geoffrey (1969): A Linguistic Guide to English Poetry. Harlow, Longman.

LotMan, Yuri (1977): The Structure of the Artistic Text. Míchigan, University of Michigan.

MCCARTHY, Kathryn S. (2015): «Reading Beyond the Lines: A Critical Review of Cognitive Approaches to Literary Interpretation and Comprehension». Scientific Study of Literature, 5:1, 99-128.

MCCARTHY Kathryn S. \& Susan R. GOLDMAN (2017): «Constructing Interpretive Inferences about Literary Text: The Role of Domain-specific Knowledge». Learning and Instruction, 60, 245-251.

Miall, David S. (2006): Literary Reading: Empirical and Theoretical Studies. Nueva York, Peter Lang.

MiALL, David S. \& Don KUIKEN (1994): «Foregrounding, Defamiliarization and Affect: Response to Literary Stories». Poetics, 22, 389-407.

MUKAROVSKY, Jan (1964): «Standard Language and Poetic Language», in P. Garvin (ed.), A Prague School Reader on Esthetics, Literary Structures and Style. Washington D.C., Georgetown University Press, 17-30.

Newen, Albert, Leon De BRUIN \& Shaun Gallagher (2018): The Oxford Handbook of $4 E$ Cognition. Oxford, Oxford University Press.

NORENZAYAN, Ara. et al. (2006): «Memory and Mystery: The Cultural Selection of Minimally Counterintuitive Narratives». Cognitive Science, 30, 531-553.

PAULSON, William (1988): The Noise of Culture: Literary Texts in a World of Information. Ithaca, Nueva York, Cornell University Press.

RICEUR, Paul (1960): Philosophie de la volonté. Finitude et culpabilité II. La symbolique du mal. París, Aubier.

RICeEUR, Paul (1965): De l'interprétation : essai sur Freud. París, Éditions du Seuil.

RICCEUR, Paul (1969): Le conflit des interprétations : essais d’herméneutique. París, Éditions du Seuil.

RICEUR, Paul (1971): «Preface», in D. Ihde (ed.), Hermeneutic Phenomenology. The Philosopher of Paul Ricour. Illinois, Northwestern University Press.

RICEUR, Paul (1974): «Existence and Hermeneutics», in D. Ihde (ed.), The Conflict of Interpretations. Evanston, Northwestern University Press, 3-26.

RICEUR, Paul (1975): La métaphore vive. París, Éditions du Seuil. 
RICEUR, Paul (1976): «Ideology, Utopia and Faith». The Centre for Hermeneutical Studies, 17, 21-28.

RiceEur, Paul (1983): Temps et Récit, Tome. I. Paris, Éditions du Seuil.

SCHLEIERMACHER, Friedrich (1998): Hermeneutics and Criticism. Cambridge, Cambridge University Press.

SCHROTT, Raoul \& Arthur M. JACOBS (2011): Gehirn und Gedicht: Wie wir unsere Wirklichkeiten konstruieren. Berlín, Hanser.

ScotT-BAumann, Alison (2009): Ricœur and the Hermeneutics of Suspicion. New York, The Continuum London.

SEDGWICK, Eve Kosofsky (1997): «Paranoid Reading and Reparative Reading, or, You're So Paranoid, You Probably Think This Essay Is About You», in E. Sedgwick (ed.), Novel Gazing: Queer Readings in Fiction. Durham, Duke University Press, 1-37.

SPERBER, Dan Sperber \& Deirdre WILSON (1995): Relevance: Communication and Cognition. Oxford-Cambridge, Blackwell.

THELEN, Esther et al. (2001): «The Dynamics of Embodiment. A Field Theory of Infant Perseverative Reaching». Behavioral and Brain Sciences, 24, 1-86.

TURNER, Mark (2014): The Origin of Ideas. Blending, Creativity and the Human Spark. Nueva York, Oxford University Press.

VAN DIJK, Teun \& Walter KINTSCH (1983): Strategies of Discourse Comprehension. Nueva York-Londres, Academic Press.

ZWANN, Rolf A. (2016): «Situation Models, Mental Simulations and Abstract Concepts in Discourse Comprehension». Psychonomic Bulletin \& Review, 23, 1028-1034.

ZWANN, Rolf A. et al. (2010): «Motor Resonance as a Function of Narrative Time: Further Tests of the Linguistics Focus Hypothesis». Brain and Language, 112, 143149. 